\title{
Medical Internship Training Programme in a Medical College - Voice of Internees: Mixed Model research
}

\author{
Goyal, R. C. ${ }^{1}$, Khapre, M.P. ${ }^{2}$, Mathur, M.V.. ${ }^{3}$ Mudey, A.B. ${ }^{4}$, Tankhiwale, S.R. ${ }^{5}$
}

\begin{abstract}
Context: The interns after completion of rotatory training programmes are often reported to be noncompetent and lacking in clinical skills to work independently in the community. Internship training in India is facing serious challenges such as faulty/virtually no curriculum for medical interns, disinterested learners and lethargic attitudes in programme implementation.
\end{abstract}

Aims: To collect and analyse the perceptions/opinions and attitude of learners (Medical Interns) on teaching, learning and evaluation of the current Medical Internship Training Programme.

Methods and Material: Qualitative data were collected by focus group discussions while the quantitative data were collected by a self-rated perception scale. Content and domain analysis was done for qualitative data and descriptive statistics was used for quantitative data.

Results: Respondents reported no formal teaching and poor learning of skills. Interns were not required to deal with medico legal cases and emergencies during the training period. Work based evaluation was not done routinely and there was a lack of supervision and involvement of senior faculty in training. Communication with patients was very minimal due to hectic working pattern with no time for pre-PG preparation. The working environment was unsafe and interns were not confident to work independently as community physicians.

Conclusions: Interns perceive the training program as very poorly implemented and producing semiskilled doctors with less confidence in clinical and non-clinical skills and competencies.

Key-words: Internship, teaching, learning, evaluation

\section{Introduction}

The Medical Council of India (MCl) describes internship as "a phase of training wherein a graduate is expected to conduct actual practice of medical and health care and acquire clinical and nonclinical skills under supervision so that he/she may become capable of functioning independently" (MCl, 1997).

${ }^{1}$ Professor and Director, Department of Community Medicine, J N Medical College, India

${ }^{2}$ Assistant Professor, Department of Community Medicine, J N Medical College, India

${ }^{3}$ Resident, Department of Community Medicine, J N Medical College, India

${ }^{4}$ Professor\& Head, Department of Community Medicine, $J$ N Medical College, India

${ }^{5}$ Director, SHPER, Datta Meghe Institute of Medical Sciences, Wardha, Maharashtra, India

Corresponding Author:

Meenakshi P Khapre, Department of Community Medicine, J N Medical College, India

Email:drmeenaxi15@ymail.om
Competency based learning includes designing and implementing a medical education curriculum that focuses on the desired and observable ability to perform in real life situations. In order to effectively fulfil the above roles the medical student would have obtained following set of competencies at the time of graduation from the M.B.B.S. programme:

1. Clinician, who understands and provides preventive, promotive, curative, palliative and holistic care with compassion.

2. Leader and member of the health care team and system with capabilities to collect, analyze and synthesize health data.

3. Communicator with patients, families, colleagues and community.

4. Lifelong learner committed to continuous improvement of skills and knowledge.

5. Professional, who is committed to excellence, is ethical, responsive and accountable to patients, community, and profession. 
The roles defined above are often not fulfilled due to lack of a defined curriculum for Medical Internship Training. However, clinical competencies have been defined for each subject, which they have to master. The real situation is far from the expected outcome. But at the end of internship the interns are amateurish and unreliable. This may be due to following reasons:

a) An intern is busy with his preparation for forthcoming postgraduate (PG) entrance examinations.

b) Non implementation of the Medical Internship Training Program in true spirit and letter as defined by the $\mathrm{MCl}$ statement

c) No mechanism for reinforcing of the various key skills at regular intervals such as handling emergencies, Medico-Legal cases, communication skills, leadership etc.

d) No methodology /curriculum for continuous improvement in recent knowledge and skills.

e) Lack of scheduled small or large group teaching/learning and with unsupervised learning taking place most of the time.

However, medical education and health care in India are facing serious challenges in needs based content and competencies. These challenges are multifactorial and multidimensional, some of them are,

i. Faulty/virtually no curriculum for medical interns

ii. Disinterested learner

iii. Lethargic attitude in implementation of Medical internship program etc. as concluded by Chaturvedi \& Agrawal (2001) and Lal (1999)

In the past many studies have been conducted to evaluate various stakeholders, including interns. We could find very few studies dealing with the perceptions and attitudes of learners, (interns). Hence this study was planned to identify and evaluate the perception and attitudes of learners, for better implementation of Medical Internship Training Programme across the country.

\section{Objectives}

To collect and analyse the perceptions/ opinions and attitude of learners (Medical Interns) on teaching, learning and evaluation of the current Medical Internship Training Programme.

\section{Subjects and Methods}

The study was conducted at a care Medical College and teaching hospital in India with medical interns as study participants. The variables used were perceptions/opinions and attitudes regarding teaching (class room, hands-on, demonstration and PG preparation), learning (discussions, rounds, managerial and soft skills) and evaluation (knowledge, skills and attitudes), monitoring and supervision, communication skills, safety at work, motivation to work as a community physician, confidence to work independently, pre-PG exam preparation and suggestions for modification of the syllabus/ evaluation /period etc. Data were collected using both qualitative and quantitative methods.

Qualitative data were obtained by ten focus group discussions (FGD) conducted following standard FGD guidelines. Each FGD had 10-12 members and average time taken was 60-75 minutes. The responses were noted on FGD formats. The verbatim responses were changed to English for wider understanding by the readers. Data was then analysed using content and domain analysis.

Quantitative data were collected using a pre tested and validated self-administered questionnaire rated with Likert scales. The responses on perception and attitude of Medical Interns, were obtained on 5 point Likert scale $(S A=$ Strongly Agree - score $=5, A=$ Agree - score $=4, N=$ Neutral - score $=3, D=$ Disagree -

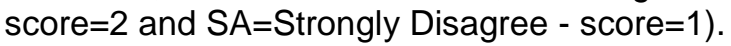
Average score was calculated for each item using the formula: Total no. of responses $X$ score assigned / total respondents. An average score of more than $>3$ was considered as significant / effective. This data was analysed using the descriptive statistics.

\section{Results}

\section{Qualitative}

A total of 10 FGDs were conducted with medical interns, involving 110 participants. The content of perceptions/ feelings and suggestions were divided in the domains of Teaching, Learning, Evaluation, Monitoring and supervision, Communication skills, Safety at work, Motivation to work as community physician, Confidence to work independently, Pre-PG exam preparation and suggestions for Modification in syllabus/ evaluation /period etc. 


\section{Intern's responses}

\section{Teaching}

- Nobody taught me, not even $10 \%$ of what is expected

- We just draw the blood samples and assist with investigations

- No seniors teach us

- Resident asks to get high risk consent written without knowing its importance

- Nobody has time for us and we work like attendants

- Nobody taught us how to handle basic equipment like ECG machines

- We know only MS software but there was no training for hospital software

- Casualty posting is only for namesake

Interpretation and suggestions

- There is no formal teaching schedule

- There is no staff allocation for teaching

- Suggestion given: Formal teaching schedule (may be one hour per day for theory and discussion) to be prepared and HOD (Head of Department) should be responsible

\section{Learning}

- Interns are not allowed to attend daily ward rounds

- We are allowed to conduct deliveries

- We had not even learned the basic skills that are mentioned in the log book

- We have no experience with medicolegal cases; never saw a death certificate or injury reports

- We only do clerical work

- The year was just wasted without learning

Interpretation and suggestions

- Learning of clinical skills is very poor

- Training in medico-legal aspects and emergency management are lacking

- Suggestion given: All departments should take efforts to prepare effective learning

\section{Evaluation}

1. Day to day activity is not evaluated and completion only depends on attendance which is marked by a junior resident as his wish

2. Evaluation is done for namesake

Interpretation and suggestions

- Workplace based evaluation is not done

- Day to day WPBE (Work performance based examination) to be done

\section{Monitoring and supervision}

- Only junior most PG students supervise

- The PGs treat us as helpers without a brain and at times trouble us

\section{Communication skills}

- We only communicate with Junior PGs

- We do not even interact with patients in the OPD

- We only collect blood for investigations from IPD patients without even getting a clinical history

\section{Safety at work}

- We learn during the "Rural posting" but safety is an issue

- We should have all measures for our safety at work including hepatitis immunization, Personal Protective Equipment while dealing with HIV positive patients etc.

\section{Motivation to work as community physician}

- We do not want to work in rural area as facilities (physical, education amenities) are not available

- We want to do PG in clinical specialties only and earn money

\section{Confidence to work independently}

- We are not confident, not even $10 \%$

- We felt like doctors in the rural posting and had little confidence

- $\quad P G$ entrance is a hurdle for working and gaining confidence

\section{Pre-PG exam preparation}

- We do not get time to prepare for PG entrance as duty schedule is hectic

- We have to go to wards as and when called by PGs

\section{Modification in Internship Training Program}

- Close watch over the internship training activity in all the department by some senior responsible persons

- Even if the senior teacher is busy he can allocate the responsibility to his resident to teach some basic skills as given in the log book and then evaluate it from interns whether the resident taught them or not

- Assessment of training should be completed by staff at each posting by concerned department and discussed in college council meetings

- distribution of time in such a manner so that there is some time for self-study for PG preparation

- 8 hour duty (three shift) for interns to be implemented 


\section{Quantitative}

Average score of all the items as given in table 1 , were $>3$ except for the item "internship training helped learner to effectively deal with medical emergencies and ethical issues". The research project given during the internship training and rural postings was greatly appreciated by interns.

Table 1: Perception and Attitude of Interns towards internship training programme

\begin{tabular}{|c|c|c|c|c|c|c|c|}
\hline & Particulars & $\begin{array}{c}\text { S A } \\
\%\end{array}$ & $\begin{array}{l}\mathbf{A} \\
\%\end{array}$ & $\begin{array}{l}\mathbf{N} \\
\%\end{array}$ & $\begin{array}{l}\mathbf{D} \\
\%\end{array}$ & $\begin{array}{l}\text { S D } \\
\%\end{array}$ & $\begin{array}{l}\text { Avg } \\
\text { Score }\end{array}$ \\
\hline 1 & $\begin{array}{l}\text { The internship training provided to me with } \\
\text { relevant knowledge and practical training to assist } \\
\text { me in becoming better and confident physician in } \\
\text { future }\end{array}$ & 8.4 & 41.6 & 50.0 & 00 & 00 & 3.58 \\
\hline 2 & $\begin{array}{l}\text { The internship training help me to relate theories } \\
\text { learned in classroom to work environment }\end{array}$ & 8.4 & 50.0 & 41.6 & 00 & 00 & 3.67 \\
\hline 3 & $\begin{array}{l}\text { The internship training help me to master clinical } \\
\text { skills like I.V, Injection, catheterisation etc }\end{array}$ & 8.4 & 25.0 & 41.6 & 25 & 00 & 3.16 \\
\hline 4 & $\begin{array}{l}\text { The internship training help me to enhance my } \\
\text { knowledge on basic medical ethics and principle }\end{array}$ & 00 & 33.3 & 25.0 & 33.3 & 8.4 & 2.98 \\
\hline 5 & $\begin{array}{l}\text { The internship training help me to practice rational } \\
\text { use of medicine }\end{array}$ & 25.0 & 25.0 & 41.6 & 8.4 & 00 & 3.67 \\
\hline 6 & $\begin{array}{l}\text { The internship training help me to develop my } \\
\text { communication skill and better interaction with } \\
\text { patients }\end{array}$ & 8.4 & 25 & 41.6 & 25.0 & 00 & 3.16 \\
\hline 7 & $\begin{array}{l}\text { The internship training help me to effectively deal } \\
\text { with medical emergencies }\end{array}$ & 8.4 & 00 & 00 & 91.6 & 00 & 2.25 \\
\hline 8 & $\begin{array}{l}\text { The internship training gave me insight for } \\
\text { research methodology }\end{array}$ & 41.6 & 25.0 & 25.0 & 8.4 & 00 & 4.00 \\
\hline 9 & $\begin{array}{l}\text { The internship training expose me to recent } \\
\text { advances in medical technologies }\end{array}$ & 00 & 33.3 & 58.3 & 8.4 & 00 & 3.33 \\
\hline 10 & $\begin{array}{l}\text { The internship training help me to understand and } \\
\text { sensitise to rural health needs }\end{array}$ & 50.0 & 8.4 & 41.6 & 00 & 00 & 4.10 \\
\hline
\end{tabular}

${ }^{*} \mathrm{SN}=$ strongly agree; $A=$ Agree; $N=$ neutral; $D=$ Disagree; $S D=$ strongly disagree

\section{Discussion}

Rotatory Internship Training Program is an integral and mandatory part of a successful MBBS training program (MCl, 1997). This period of training which includes a sudden change of responsibility and accountability, is supposed to be under supervision and mentoring. This study showed the perceptions, feelings and attitude towards conduct of the Internship Training program.

The Interns reported no formal teaching/ training time table at departmental level; nobody was assigned the duty for responsible supervision, they were not allowed to do the clinical work, and required to do non-clinical assignments and casual evaluation. Interns were not confident in communication or emergency management skills and reported inability to work independently during and after internship. They opined that if interns were posted 8 hours in rotation, then PG preparation time will be adequate. Similar findings were also reported by Bansal (2004), Bhavsar (2010), Giri and Parhar (2012), Shreshta and Mishra (2008).

Other authors such as Simon (1992), Lal (1999) and Chaturvedi and Aggarwal, (2001) reported that the majority of interns do not actively participate in the internship period because in many States of India, the graduate medical doctors have to take a written examination for pursuance of post-graduate studies.

Content and domain analysis of qualitative data showed that some domains like TLE (Teaching, Learning \& Evaluation), Ethics \& Ethical practice, Communication skills, Team Work to be emphasized more than non-clinical domains.

Quantitative analysis through Likert scale and subsequent average scoring (majority of items had average >3.00) showed impact of Internship Training on learning but it was also observed that many respondents gave neutral 
responses. Interns were well satisfied with rural training as also quoted by intern in the FGD. It was only after completion of rural internship that they felt confident in interacting with and treating the patient.

In the FGDs, interns were mostly interested in hospital posting scenarios and would discuss of rural posting only on probing. Positive impact of this rural posting might be depicted in the attitude of interns resulting in some mismatch in qualitative and quantitative analysis.

\section{Conclusions and suggestions}

The Internship training program was very poorly implemented and producing semi-skilled doctors with less confidence in clinical and nonclinical skills and competencies.

The authors propose 10 points to strengthen the Internship Training program on the basis of findings of present study as well as reports of poor implementation in other parts of India too as quoted by Bansal (2004), Bhavsar (2010) and the National Knowledge Commission (2011).

1. Interns should be posted in clinical skill laboratories for hands-on training.

2. The Intern training curriculum should be well defined with an adequate level of proficiency and competency to be attained in various skills along with formative and summative evaluation in each posting.

3. Interns should be the part of daily rounds by teaching faculty.

4. Day to day Workplace Based Evaluation to be done, for example directly observed procedural skill (DOPS), case based discussion (CBD) etc. by teaching faculty.

5. Evaluation of soft skills can be done through the communication skills lab.

6. Ethics, etiquette and behaviour, patient charter, relevant health act, policies and schemes, medico-legal aspects and emergency management to be included in their learning.

7. Time allocation for self-directed learning along with dedicated classes for PG preparation.
8. On the basis of performance analysis of interns, $10 \%$ weightage be given for Pre PG examination.

9. Motivational opportunities to be provided such as quota for PG, facilities etc. to work in rural areas after completion of Internship.

10. Process of providing regular feedback from interns and vice versa should be implemented to improve interns' learning, education and satisfaction.

\section{References}

Bansal, R.K. (2004) Need for Strengthening of Internship (Rotatory Housemanship) Training in India, Education for Health, 17, 3, pp. 332-338.

Bhavsar, B.S. (2010) Internship Training (editorial), Healthline, 1, p. 3.

Chaturvedi, S. \& Agrawal, O.P. (2001) Training interns in population-based research: learners' feedback from 13 consecutive batches from a medical school in India, Medical Education, 35, 6, pp. 585-589.

Lal, S. (1999) Innovative approaches in the pursuits of teaching-training and research in community medicine, Indian Journal of Community Medicine, 24, pp. 8-18.

Medical Council of India (1997) Salient features of regulations on graduate medical education, New Delh, India: MCl.

Giri, P.A. \& Parhar, G. (2012) Internship: a transition from a medical student to a doctor, International Journal of Biomedical and Advance Research, 3, 10, pp. $753-755$.

National Knowledge Commission (2011) Report of the working group on medical education, Government of India [Online] Available at http://knowledgecommission.gov.in/downloads/ documents/wgmed.pdf [Accessed 15th Jan 2014]

Shrestha, D. \& Mishra, B. (2008) Learning, education and satisfaction after compulsory rotating internship in Kathmandu University Medical School: a qualitative study of interns' response, Kathmandu University Medical Journal, 6, 2, pp. 284-290.

Simon, H.H. (1992) Medical education: Does it serve the purpose, Yojana, Special Issue on Health for All, pp. 16-32 [Online] Available at www.mciindia.orgknow/rules/rules_mbbs.htm [Accessed: 15 Jan 2014]. 